\title{
Maternal and neonatal outcome of twin pregnancy at a tertiary care center
}

\section{Vaishali Chaudhary*, Kamalpriya Thiyagarajan, Yogini Patil, Vijaykumar Gawali}

Department of Obstetrics and Gynaecology, Bhaktivedanta Hospital and Research Institute, Mira Road, Mumbai, Maharashtra, India

Received: 23 October 2021

Accepted: 13 November 2021

\section{*Correspondence:}

Dr. Vaishali Chaudhary,

E-mail: drvaishali231980@gmail.com

Copyright: ( ) the author(s), publisher and licensee Medip Academy. This is an open-access article distributed under the terms of the Creative Commons Attribution Non-Commercial License, which permits unrestricted non-commercial

\begin{abstract}
Background: Twin pregnancies occurs in 2 to $4 \%$ of the total number of births. Also the perinatal mortality and morbidity associated with it is five to six times higher in comparison with singleton pregnancy. In developing countries, 287,000 annual maternal deaths and 3 million neonatal deaths contributes to $99 \%$ of such mortality as per records of the World Health Organization (WHO) estimates that $99 \%$ of the world's annual occur in developing countries.

Methods: This observational study included 50 women with twin pregnancy with gestational age of 26 weeks or more. Maternal and neonatal characteristics in twin deliveries at a tertiary care center were analyzed. High risk factors and it's association with maternal and perinatal outcomes was analyzed.

Results: Pregnancy induced hypertension (32\%) was the commonest, Preterm rupture of membranes (PROM, 22\%) was in the next order. Invitro fertilization $(44 \%)$, malpresentation $(26 \%)$ main indicators for lower segment cesarean section. Mean weight of first twin was $1.9 \pm 0.43 \mathrm{~kg}$ and for second twin it was $1.89 \pm 0.47 \mathrm{~kg}$ (Table 1). Most of twins were diamniotic dichorionic (78\%).

Conclusions: Twin pregnancies are hazardous to both for the mother and the neonate. It is certainly high risk factor which needs early identifications of complications and timely management. Perinatal outcome largely depends on gestational age, birth weight, presentation, mode of delivery.
\end{abstract}

Keywords: Twin pregnancy, Multiple pregnancy, Neonatal outcome

\section{INTRODUCTION}

Twin pregnancies occurs in 2 to $4 \%$ of the total number of births, however its prevalence is less than 8 twin pregnancies per 1,000 births in the East, Southeast and Southern Asia, including India. ${ }^{1-4}$ Twin pregnancy is becoming a challenging due to its increase in incidence quite often attributed to assisted reproductive technologies (ARTs).5 Also the perinatal mortality and morbidity associated with it is five to six times higher in comparison with singleton pregnancy. ${ }^{6-8}$

Intrauterine fetal death, congenital malformations, prematurity, low birth weight (LBW-contributed by both prematurity and IUGR birth trauma), birth asphyxia are few of the reasons for high mortality. It also contributes to increased obstetric and perinatal complications such as, post-partum hemorrhage, preeclampsia and preterm birth..$^{4,8-11}$

In developing countries, 287,000 annual maternal deaths and 3 million neonatal deaths contributes to $99 \%$ of such mortalities globally as per records of the World Health Organization (WHO). ${ }^{12,13}$ In comparison to the past, current increase in incidence of twin pregnancy has been attributed to ART, increase in the use of ovulation inducing agents, a shift toward bearing children at older maternal ages. ${ }^{14-16}$ Objective of this study is to evaluate the feto-maternal outcome of twin pregnancies at tertiary care centre. 


\section{METHODS}

\section{Study ethics and design}

The study was initiated after obtaining approval from the Institutional Ethics Committee and approval from the Ministry of Health. The study was a retrospective, observational study carried out for data duration January 2018 to December 2020. We adhered to the latest update of Declaration of Helsinki guidelines.

\section{Study participants}

Medical records for adult (>18 years) pregnant women with twin pregnancies (confirmed by ultrasound examination) who were admitted in the hospital were reviewed. We examined maternal and neonatal characteristics in twin deliveries.

Data was not considered for patient with pre-existing medical complication like chronic hypertension, collagen vascular disease, diabetes mellitus, renal disease, or any other disorder that may adversely affect the present pregnancy, also congenital anomalies in either fetus excluded.

\section{Study procedure}

Study team analyzed Case record form, antenatal records, past health records, investigation reports. Investigator analyzed data archived in medical record dept regarding Maternal aspects such as age, weight, primigravida, multigravida, gestational periods, complications such as pregnancy induced hypertension, preterm rupture of membranes (PROM), anemia, gestational diabetes, hypothyroidism, Cervical Circlage, antepartum hemorrhage. Data regarding malpresentation, preeclamsia, previous LSCS, premature rupture of membrane, preterm delivery, and normal delivery were reviewed. Fetal aspects such as weight, IUGR, need of NICU. All relevant data were recorded and analyzed statistically by simple proportions.

\section{RESULTS}

During the study period of 36 months there were 2688 deliveries including 50 twin deliveries, giving the incidence of twin $1.86 \%$. The mean maternal age was $25.25 \pm 1.8$ years for twin pregnancies. Mean gestational age of delivery was $34.57 \pm 1.94$ weeks (Table 1 ).

Among major maternal complications pregnancy induced hypertension $(32 \%)$ was the commonest, Preterm rupture of membranes (PROM, 22\%) was in the next order, followed by anemia (20\%), gestational diabetes (2\%), hypothyroidism (18\%), Cervical Circlage (12\%), Antepartum hemorrhage (APH, 2\%) (Table 2).

Among Indications for Lower segment cesarian section (LSCS), Invitro fertilization (44\%) was the commonest, malpresentation (26\%) was in the next order, followed by previous LSCS (10\%), intrauterine growth retardation $(8 \%)$, premature rupture of membrane $(4 \%)$, pre-eclampsia (4\%), (Figure 1).

Table 1: Demographic characteristics of the study population. $\alpha$-represented in $\mathbf{n}(\%)$, all others are represented in mean $(\mathrm{SD})$.

\begin{tabular}{|ll|}
\hline Demographic characteristics & N $(\%)$ \\
\hline Mean age (years) & $25.25(1.88)$ \\
\hline Primigravida $^{\boldsymbol{\alpha}}$ & $33(66)$ \\
\hline Multigravida $^{\boldsymbol{\alpha}}$ & $17(34)$ \\
\hline Gestational period (weeks) & $34.57(1.94)$ \\
\hline Weight first child (kg) & $1.9(0.43)$ \\
\hline Weight second child (kg) & $1.89(0.47)$ \\
\hline
\end{tabular}

Table 2: Maternal and fetal complications; represented in $\mathbf{n}(\%)$.

\begin{tabular}{|ll|}
\hline Maternal and fetal complications & N $(\%)$ \\
\hline Pregnancy induced hypertension & $16(32)$ \\
\hline $\begin{array}{l}\text { Preterm rupture of membranes } \\
\text { (PROM) }\end{array}$ & $11(22)$ \\
\hline Anemia & $10(20)$ \\
\hline Gestational diabetes & $10(20)$ \\
\hline Hypothyroidism & $9(18)$ \\
\hline Cervical circlage & $6(12)$ \\
\hline Antepartum hemorrhage & $1(2)$ \\
\hline NICU Admission & $15(30)$ \\
\hline Neonatal Deaths & $0(0)$ \\
\hline
\end{tabular}

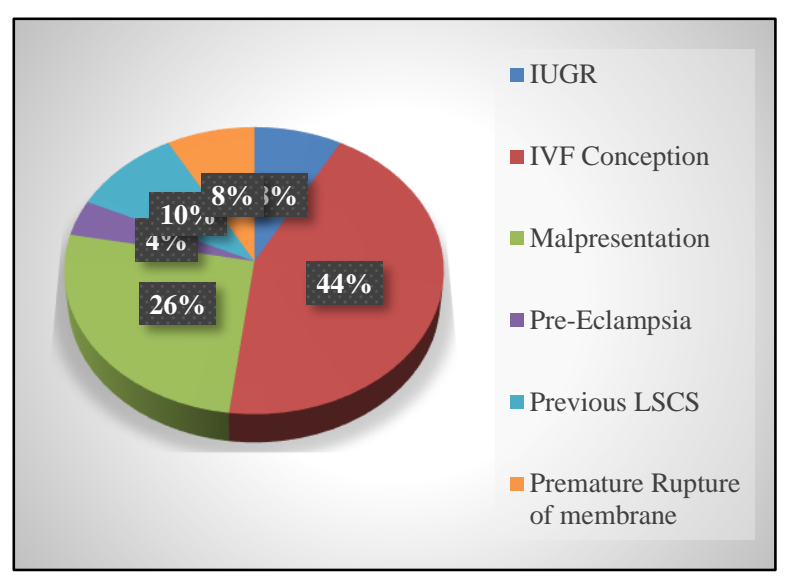

Figure 1: Indication of LSCS.

Caesarean section was performed on forty-six (92\%) women, three $(6 \%)$ had full term normal delivery and one (2\%) delivered preterm (Figure 2).

\section{Neonatal outcome}

Mean weight of first twin was $1.9 \pm 0.43 \mathrm{~kg}$ and for second twin it was $1.89 \pm 0.47 \mathrm{~kg}$ (Table1). Most of twins were diamniotic dichorionic ( $78 \%$ ), followed by monoamniotic 
monochorionic pregnancy (18\%) and conjoined twin (4\%) (Figure 3).

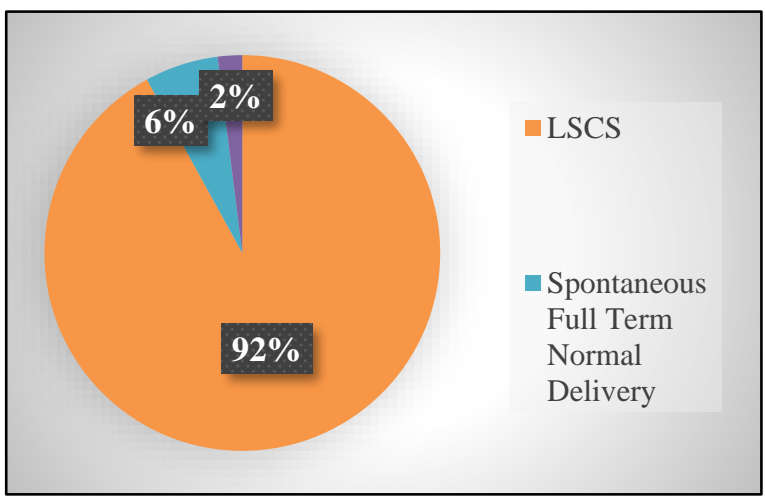

Figure 2: Delivery type in (in percentage).

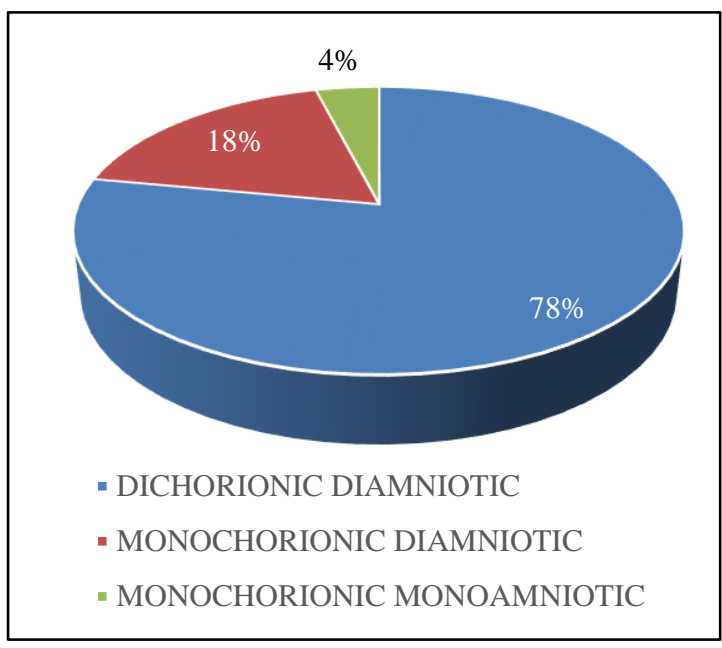

Figure 3: Distribution of patients by type of chrionicity (in percentage).

\section{DISCUSSION}

Health risks for both mothers and babies are far more in twin or multiple births, and also accompanying greater health care cost makes it important topic to deliberate. ${ }^{17}$ This higher incidence of twins in our study is attributed to invitro fertilization (44\%) (Figure 1) which is similar in earlier studies. $^{18}$ ART-associated twins have lower perinatal mortality than spontaneously conceived twins is observed however few studies mentions comparable perinatal outcome as with naturally conceived twins in our study deliveries prior to 28 weeks were excluded. ${ }^{19-21}$ Advancing age is considered as one of the important factor in twin pregnancy which is not the case in our study, also also that various authors have different opinions on it. ${ }^{22-24}$

Our study reports $66 \%$ primigravida and $34 \%$ multigravida which is contrary to already published study in which $84.2 \%$ were multigravida another study reported $45.7 \%$ primigravida and $54.3 \%$ multigravida. ${ }^{25,26}$ Studies reported preterm delivery in $60 \%$ and $67 \%$ of twin pregnancies and few other studies reported even lower $38 \% 29$ and $44 \% 30$, which is in line with our study. Studies have reported cesarean section (LSCS) in $68 \%, 49 \%$ and $45 \%$ where as our study reports it as $92 \% .^{27-31}$

In our study most common mode of delivery is LSCS, few studies reported that mode of delivery is a significant predictor of perinatal outcome, however this predictor is not quite conclusive, as conflicting results are published in other few studies. ${ }^{31,32}$ Pregnancy induced hypertension(PIH) was observed in $32 \%$ twin pregnancy in our study which was similar to study published earlier which reported $40 \% \mathrm{PIH} .{ }^{33}$ Preterm rupture of membranes (PROM) was observed in $22 \%$ cases in our study and it was reported higher in few other studies $31.81 \%$ and $38 \% .{ }^{30,33}$ Our study reports gestational diabetes $20 \%$ while one of the study has reported it very low which is $1.8 \%$. Presentation in labor is important factor in intrapartum management. ${ }^{34}$ NICU admissions was reported as $65.15 \%$ neonates which was similar to another study $66 \%$ however in our study it was $30 \% .^{33-35}$

\section{Limitations of the study}

Limitations of this study were less sample size and retrospective design of the study.

\section{CONCLUSION}

Twin pregnancies are hazardous to both for the mother and the neonate. It is certainly high risk factor which needs early identifications of complications and timely management. Perinatal outcome largely depends on gestational age, birth weight, presentation, mode of delivery.

\section{Funding: No funding sources}

Conflict of interest: None declared

Ethical approval: The study was approved by the Institutional Ethics Committee

\section{REFERENCES}

1. Walker MC, Murphy KE, Pan S, Yang Q, Wen SW. Adverse maternal outcomes in multifetal pregnancies. BJOG. 2004;111(11):1294-6.

2. Young BC, Wylie BJ. Effects of twin gestation on maternal morbidity. Semin Perinatol. 2012;36(03):162-8.

3. Collins J. Global epidemiology of multiple birth. Reprod Biomed Online. 2007;15(3):45-52.

4. Smits J, Monden C. Twinning across the developing world. PLoS One. 2011;6(09):e25239.

5. Aziz S, Soomro N. Twin births and their complications in women of low socioeconomic profile. J Pak Med Assoc. 2012;62:1204-8.

6. Dutta DC. Text book of obstetrics including perinatology and contraception. 6th ed. Calcutta: New Central Book Agency (P) Ltd. 2004.

7. Minakami H, Sato I. Re-estimating date of delivery in multifetal pregnancies. JAMA. 1996;275(18):1432-4. 
8. Ashworth MF, Spooner SF, Verky DA, Waterman R, Ashurst HM. Failure to prevent preterm labour and delivery in twin pregnancy using prophylactic oral. $\mathrm{Br}$ J Obstet Gynaecol. 1990;97(10):878-82.

9. Sumathipala A, Siribaddana S, De Silva N, Fernando $\mathrm{D}$, Abeysingha N. Sri Lankan twin registry. Twin Res. 2002;5:424-6.

10. Aisien A, Olarewaju R. Twins in Jos Nigeria: a sevenyear retrospective study. Med Sci Monit. 2000;6:94550 .

11. Obiechina N, Okolie V, Eleje G. Twin versus singleton pregnancies: the incidence, pregnancy complications, and obstetric outcomes in a Nigerian tertiary hospital. Int J Womens Health. 2011;227-30.

12. World Health Organization. UNiCEF, UNFPA, World Bank. Trends in Maternal Mortality: 1990 to 2010. World Health Organization. 2012.

13. UNiCEF, World Health Organization, World Bank, United Nations (2012) Levels and Trends in Child Mortality Report 2012. UNICEF. 2012.

14. Chittacharoen. A pregnancy outcome of twin pregnancy in Ramathibodi hospital. Journal of Med assoc Thai. 2006;89:576-80.

15. American society of reproductive medicine. Multiple pregnancy and birth, considering infertility treatment: twin, triplets and higher order multiples. 2004.

16. Hofmeyr GJ, Barret JF, Crowther CA. Planned caesarean section for women with a twin pregnancy. Cochrane database syst rev. 2011;(12):CD006553.

17. The ESHRE Capri Workshop Group. Multiple gestation pregnancy. Hum Reprod. 2000;15:1856-64.

18. Sultana H. Fetal and maternal outcome of twin pregnancy-A study of 50 cases. Bangladesh college of Physicians and Surgeons, Dhaka. 1998.

19. Brian P, Fitzsimmons MD, Michael W, Bebbington MD, Margo R, Fluker MD. Perinatal and neonatal outcomes in multiple gestations: Assisted reproduction versus spontaneous conception. Am J Obstet Gynecol. 1998;179:112-7.

20. Olivennes F, Kadhel P, Rufat P, Fanchin R, Fernandez H, Frydman R. Perinatal outcome of twin pregnancies obtained after in vitro fertilization: Comparison with twin pregnancies obtained spontaneously or after ovarian stimulation. Fertil Steril. 1996;66:105-9.

21. Koudstaal J, Bruinse HW, Helmerhorst FM, Vermeiden JP, Willemsen WN, Visser GH. Obstetric outcome of twin pregnancies after in-vitro fertilization: A matched control study in four Dutch University hospitals. Obstet Gynecol. 2004;103:114453.

22. Blickstein I, Goldman RD, Mazkereth R. Maternal age and birth weight characteristics of twins born to nulliparous mothers: a population study. Twin Res. 2001;4:1-3.

23. Zhang J, Meikle S, Grainger DA. Multifetal pregnancy in older women and perinatal outcomes. Fertil Steril. 2002;78:562-8.

24. Branum AM, Schoendorf KC. The influence of maternal age on very preterm birth of twins: differential effects by parity. Paediatr Perinat Epidemiol. 2005;19:399-404.

25. Pellacy WN, Handler A, Ferre CD. A case control study of 1253 twin pregnancies from 1982-1987. Perinatal Data Base. 1990;75:198-71.

26. Dubey S, Mehra R, Goel P, Rani J, Satodiya M. Maternal complications in twin pregnancy; recent trends: a study at a tertiary care referral institute in Northern India. Int J Reprod Contracept Obstet Gynecol. 2018;7:3753-7.

27. Deepthi HR, Pradeep MR, Lalitha S. Retrospective study of maternal and perinatal outcome of twin pregnancy in a teaching hospital. J Dental Med Sci. 2015;14(1):29-32.

28. Nandmer GK, Kanhere AV. Study of obstetric and fetal outcome of twin pregnancy in a tertiary care centre. Int J Reprod Contracept Obstetr Gynecol. 2017;4(6):1789-92.

29. Shetty MB, Shivananjaiah C, Swarup A. A retrospective study: twin gestation at tertiary care, maternal and fetal outcome. Int J Reprod Contracept Obstetr Gynecol. 2016;5(1):217-9.

30. Chowdhury S, Hussain MA. Maternal complications in twin pregnancies. Mymensingh Med J. 2011;20(1):83-7.

31. Yang Q, Wen SW, Chen Y. Neonatal mortality and morbidity in vertex-vertex second twins according to mode of delivery and birth weight. J Perinatol. 2006;26:3-10.

32. Peaceman AM, Kuo L, Feinglass J. Infant morbidity and mortality associated with vaginal delivery in twin gestations. Am J Obstet Gynecol. 2009;200:462.e1-6.

33. Zanjade TS, Bezbaruah M, Rai S, Mane JD. Twin pregnancies: a retrospective analysis. Int J Reprod Contracept Obstet Gynecol. 2021;10:1828-31.

34. Robinson C, Chauhan SP. Intrapartum management of twins. Clin Obstet Gynecol. 2004;47:248-62.

35. Bhalla S, Bhatti SG, Devgan S. Obstetric and perinatal outcome of twin pregnancy: a prospective study in a tertiary care hospital in North India. Int J Reprod Contracept Obstet Gynecol. 2018;7:2455-61.

Cite this article as: Chaudhary V, Thiyagarajan K, Patil Y, Gawali V. Maternal and neonatal outcome of twin pregnancy at a tertiary care center. Int J Reprod Contracept Obstet Gynecol 2021;10:4545-8. 